\title{
Diagnostic Reference Levels for Diagnostic and Interventional X-Ray Procedures in Germany: Update and Handling
}

\section{Diagnostische Referenzwerte für diagnostische und interventionelle Röntgenanwendungen in Deutschland: Aktualisierung und Handhabung}

Authors

Alexander Schegerer ${ }^{1}$, Reinhard Loose ${ }^{2}$, Lothar J. Heuser ${ }^{3}$, Gunnar Brix $^{1}$

Affiliations

1 Department of Medical and Occupational Radiation Protection, Federal Office for Radiation Protection, Neuherberg, Germany

2 Institute for Radiology and Nuclear Medicine, Paracelsus Medical University, General Hospital Nuremberg, Germany

3 Diagnostic and Interventional Radiology, Ruhr-Universität Bochum, Germany

Key words

patient exposure, dose optimization and reduction, diagnostic reference levels (DRLs), diagnostic and interventional radiology, pediatric $\mathrm{X}$-ray examinations

received 08.02.2018

accepted 18.11.2018

Bibliography

DOI https://doi.org/10.1055/a-0824-7603

Published online: 21.1.2019

Fortschr Röntgenstr 2019; 191: 739-751

(c) Georg Thieme Verlag KG, Stuttgart · New York

ISSN 1438-9029

Correspondence

Dr. Alexander Schegerer

Abteilung für medizinischen und beruflichen Strahlenschutz, Bundesamt für Strahlenschutz, Ingolstädter Landstraße 1, 85764 Neuherberg, Germany

Tel.: ++49/30/183332314

alexander.schegerer@luks.ch

\section{ABSTRACT}

Purpose Recent developments in medical technology have broadened the spectrum of X-ray procedures and changed exposure practice in $\mathrm{X}$-ray facilities. For this reason, diagnostic reference levels (DRLs) for diagnostic and interventional X-ray procedures were updated in 2016 and 2018, respectively. It is the aim of this paper to present the procedure for the update of the DRLs and to give advice on their practical application.

Materials and Methods For the determination of DRLs, data from different independent sources that collect dose-relevant data from different facilities in Germany were considered. Sev- en different weight intervals were specified for classifying pediatric X-ray procedures. For each X-ray procedure considered, the 25 th, 50th, and 75 th percentile of the respective national distribution of the dose-relevant parameters were determined. Additionally, effective doses that correspond to the DRLs were estimated.

Results In procedures with already existing DRLs before 2016 , the values were lowered by circa $20 \%$ on average. Numerous DRLs were established for the first time ( 9 for interventional procedures, 10 for CT examinations).

Conclusion For dose optimizations even below the new national DRLs, the BfS recommends establishing local reference levels, using dose management software (particularly in CT and interventional radiology), adapting dose-relevant parameters of X-ray protocols to the individual patient size, and establishing internal radiation protection teams responsible for optimizing X-ray procedures in clinical practice. When applying good medical practice and using modern equipment, the median dose values of the nationwide dose distributions can not only be easily achieved but can even be undercut.

Key Points:

- German diagnostic reference levels (DRLs) für diagnostic and interventional X-ray procedures were updated in 2016 and 2018, respectively.

- For X-ray procedures for which DRLs existed already before the update, the updated DLRs were lowered by circa $20 \%$, on average.

- For CT and interventional radiology, new DRLs were established.

- X-ray procedures have to be optimized even below the DRLs.

\section{Citation Format}

- Schegerer A, Loose R, Heuser LJ et al. Diagnostic Reference Levels for Diagnostic and Interventional X-Ray Procedures in Germany: Update and Handling. Fortschr Röntgenstr 2019; 191: 739-751 


\section{ZUSAMMENFASSUNG}

Ziel Die Entwicklungen der Medizintechnik in den letzten Jahren haben das Spektrum medizinischer Röntgenanwendungen erweitert und die Untersuchungspraxis in Röntgeneinrichtungen verändert. Infolgedessen wurden 2016 und 2018 die diagnostischen Referenzwerte (DRW) für diagnostische bzw. interventionelle Röntgenanwendungen aktualisiert. Ziel dieser Arbeit ist es, das Prozedere der Aktualisierung und die aktualisierten DRW vorzustellen sowie Hinweise zu ihrer praktischen Anwendung zu geben.

Material und Methoden Für die Aktualisierung der DRW wurden verschiedene, voneinander unabhängige Datenquellen berücksichtigt, die Dosis-relevante Untersuchungsparameter von verschiedenen Einrichtungen aus dem gesamten Bundesgebiet registrieren. Röntgenanwendungen an Kindern wurden in 7 verschiedene Gewichtsklassen eingeteilt. Für jede erfasste Röntgenanwendung wurde die 25., 50. und 75. Perzentile der entsprechenden nationalen Verteilung der Dosis-relevanten Untersuchungsparameter bestimmt. Für die aktualisierten und neu festgelegten DRW wurden die zugehörigen effektiven Dosiswerte abgeschätzt.

Ergebnisse Die DRW für Röntgenanwendungen, die schon vor 2016 existierten, konnten im Mittel um circa $20 \%$ gesenkt werden. Für zahlreiche Röntgenanwendungen wurden neue DRW festgelegt (für die interventionelle Radiologie 9, für die Computertomografie 10).

Schlussfolgerungen Um Röntgenanwendungen auch unterhalb der neuen nationalen DRW zu optimieren, empfiehlt das $\mathrm{BfS}$, lokale Referenzwerte festzulegen und anzuwenden, Dosismanagementsoftware (v. a. für den Bereich der CT und interventionellen Radiologie) einzusetzen, Dosis-relevante Protokollparameter der Röntgenuntersuchung bzw. des interventionell-radiologischen Eingriffs systematisch an die Patientenstatur anzupassen und einrichtungsinterne Strahlenschutzteams zu etablieren. Bei guter Praxis und Einsatz moderner Geräte-Technologien können die durch die 50. Perzentile der nationalen Verteilungen vorgegebenen Expositionsniveaus erreicht und sogar unterschritten werden.

\section{Introduction}

Approximately $95 \%$ of the radiation exposure of the population in Germany is the result of diagnostic and interventional-radiologic applications of radiation. According to estimates of the German Federal Office for Radiation Protection, the average effective dose from $\mathrm{X}$-ray procedures in Germany in 2014 was approximately $1.6 \mathrm{mSv}$ per inhabitant [1]. In particular, higher-dose radiological applications of radiation, such as computed tomography (CT) examinations and interventional-radiologic procedures, increased and made the greatest contribution to medical imaging-based radiation exposure of the population in 2014 (approximately $65 \%$ and $18 \%$, respectively). Due to the typically very small but not insignificant risk of patients developing cancer as a result of X-ray radiation [2, 3], operators of X-ray equipment must determine the indication for each individual case as well as optimize every application of radiation (ALARA "as low as reasonably achievable") [4-6]. Since medical as well as situational, procedural and equipment-related aspects are to be taken into consideration in the planning and implementation of procedures involving radiation, it can be difficult for the physician (operator) to categorize exposure values and to systematically implement optimization principles in the clinical routine.

Diagnostic reference levels (DRLs) provide users with values for optimizing the application of radiation and are intended to protect patients from excessive exposure [7, 8]. Although DRLs are not limit values but rather represent upper reference values for the purpose of orientation, it must be checked whether the radiation exposure can be reduced when the DRLs are exceeded without jeopardizing the goal of the medical procedure.

DRLs are valid for standard applications in standard patients using typical equipment. Easily measurable dose-related parameters (e. g. dose area product (DAP); volume computed tomography dose index $\left(\mathrm{CTDI}_{\text {vol }}\right)$; dose length product (DLP)) are used to define DRLs. The defined DRLs do not relate to individual radiation applications but rather to the arithmetic mean of parameter values over 10 - 20 (radiography and $\mathrm{CT}$ ) to 20 - 30 (fluoroscopy and interventional radiology) procedures performed on one device [7, 8]. As a result, interindividual differences, due for example to variations in individual patient size and in the degree of difficulty of interventional-radiologic procedures, can be reduced. The assumption is that the averaging of many patients examined on one unit approximates the exposure level for a standard patient (70 $\pm 3 \mathrm{~kg}$ [7]). Despite optimized application of radiation, the average exposure level can exceed the relevant DRL, for example, when primarily patients whose body dimensions are significantly greater than those of standard patients were examined/treated.

In Germany, the concept of DRLs for diagnostic radiology and interventional radiology is anchored in the new Radiation Protection Ordinance (§ 125 paragraph 1 StrlSchV) and also in the new Radiation Protection Act ( $\S 185$, paragraph 2, no. 2). To ensure ongoing adjustment of DRLs to the current state of the art and changes in examination practices, a cyclical process including equipment operators, the medical authorities of the German federal states, and the German Federal Office for Radiation Protection was implemented in Germany [9]. As part of quality assurance of X-ray procedures at medical facilities in accordance with $\S 130$ of the Radiation Protection Ordinance, the medical authorities check whether the methods as well as X-ray systems in use comply with the quality standards required by the current state of the art. This also includes the comparison of randomly acquired means of dose-related parameters with DRLs and a check to determine whether the achieved image quality is sufficient to answer the medical question at hand [10]. Mean values of the collected dose-related parameters are provided to the German Federal Office for Radiation Protection in anonymized form for regular updating of the DRLs. DRLs were defined for the first time in Germany in 2003 [11] and updated in 2010 [12]. Radiology equipment and the application spectrum have changed significantly since then [1] so that the DRLs for 
diagnostic and interventional X-ray procedures were updated again in 2016 and 2018, respectively [13, 14].

\section{Updating of the DRLs}

\section{Database}

Data from various sources were taken into consideration in the updates of the DRLs in 2016 and 2018:

- Medical authorities: The exposure data randomly collected by the medical authorities in their routine checks of X-ray facilities and reported to the German Federal Office for Radiation Protection were included for $\mathrm{X}$-ray procedures for which DRLs were already defined during the update in 2010. Some medical authorities also provided exposure data for conventional X-ray examinations of the shoulder and hip and for endoscopic retrograde cholangiopancreatography (ERCP) and CT examinations with bolus tracking. For mammography, the medical authorities collected data on the average dose to the breast parenchyma (average glandular dose, AGD) primarily at curative facilities. These values were compared to the dose values provided by two reference centers of the mammography screening program to the German Federal Office for Radiation Protection for the years 2012 to 2014. In total, up to multiple tens of thousands of dose values for X-ray procedures in adults were provided to the German Federal Office for Radiation Protection for the period 2010 to 2015 (e. g. shoulder level 1: 33100 DAP values, posterioranterior thorax: 22500 DAP values, mammography: 5500 AGD values, coronary angiography: 3100 DAP values, chest CT: 5900 DLP values). For pediatric examinations, between 50 (chest $C T$ in adolescents) and 1600 (conventional X-ray examination of the chest in elementary school children) values were provided. Most of the reported exposure dose values data are averages of 10 individual dose values. Dose values were averaged by medical authorities.

- Institute for Applied Quality Improvement and Research in Health Care (aQua institute): Dose-related parameters (DAP and fluoroscopy time) for interventional radiology examinations collected between 2012 and 2014 in up to 818 different inpatient facilities (1.3 million DAP values for coronary angiography, 25900 values for transcatheter aortic valve implantation) [15-17].

- German Society of Interventional Radiology and Minimally Invasive Therapy (DeGIR): Data for various minimally invasive interventions performed in up to 244 facilities between 2012 and 2017 [18, 19]. Up to 65000 DAP values for percutaneous-transluminal angioplasty (PTA) of the pelvis, thigh, and knee as well as the lower leg and foot were reported for these types of intervention.

- Survey regarding CT practice: Data for 34 standard CT examinations collected in a joint study by the German Federal Office for Radiation Protection, German Radiological Society, and the Professional Organization of German Radiologists from 2013 to 2014 [20]. Up to 600 exposure values (e. g. in the abdomen and pelvis) were taken into consideration for the individual examinations.

\section{Data analysis}

To eliminate errors (typos, assignment of the exposure data to incorrect examination types, errors in the conversion of physical units, etc.) in data collection or data transfer to the greatest extent possible, only values that were no more than a factor of three over and not less than a factor of 0.1 under the relevant DRLs from 2010 were included in the analysis. To be able to identify an erroneous allocation of DLP-CTDI ${ }_{\text {vol }}$ combinations to CT examinations, the scan lengths, $L=D L P / C T D I_{\text {vol }}$, were compared with the standard scan lengths, $L_{s t}$, of the examinations [20]. The standard scan lengths were determined on the basis of a projection with defined scan limits (e. g. from the guidelines of the German Medical Association) onto the reference woman/man defined by the International Commission on Radiological Protection (ICRP) [21]. Data sets not fulfilling the conditions $L>0.7 L_{s t}$ and $L<1.3 L_{s t}+4 \mathrm{~cm}$ were not taken into consideration [20].

The 25th, 50th, and 75th percentiles of the determined distributions of dose-related parameter values were calculated for every X-ray procedure. In addition, the effective dose, $D_{\text {eff }}$, resulting from the defined DRL was assessed based on the sex- and age-independent tissue weighting factors of ICRP publication 103 [22] using the CT-EXPO or PCXMC software for every X-ray procedure $[23,24]$. The examination parameters defined in the guidelines of the German Medical Association on quality assurance of X-ray examinations (e.g. voltage, filtering, and collimation) were taken into consideration $[25,26]$.

It must be taken into account that the average organ equivalent dose values of the male and female reference person are included in the evaluation of the calculated values for the effective dose [22]. Therefore, the calculated dose values allow comparison of different diagnostic and interventional X-ray procedures but as a rule do not allow evaluation of the individual exposure of patients with a body stature deviating from that of the reference persons. In the calculation of the effective dose for a reference person, an inaccuracy up to $30 \%$, in the interventional radiology up to $100 \%$ should be assumed [27 - 29].

\section{Special considerations in pediatric $\mathrm{X}$-ray procedures}

According to the recommendations of the ICRP, the European Commission, and the European Society of Radiology (ESR), pediatric $X$-ray procedures of the trunk are to be classified based on body weight $[8,30,31]$. Accordingly, pediatric examinations of the trunk were divided into a total of seven different weight classes ( $\triangleright$ Table 1 ) that roughly correlate with certain age groups [32]. Since only minimal data were available for some weight classes, linear correlations between the dose-related parameter values (conventional projection radiographs and fluoroscopy images: DAP, CT: current time product or $\left(T_{D I}{ }_{\text {vol }}\right.$ ) and body weight were additionally used to check the percentiles calculated from the distributions [33, 34]. Examinations of the head continued to be classified exclusively based on the patient's age.

\section{Defining the DRLs}

The DRLs were defined in an expert discussion and supplementary e-mail consultations on the basis of the collected distributions in 
- Table 1 Definition of weight classes for pediatric X-ray procedures of the trunk that roughly correspond with the age. Examinations of the head are solely classified by the patient's age.

\begin{tabular}{|l|l|l|l|l|l|l|l|}
\hline $\begin{array}{l}\text { premature } \\
\text { infant }\end{array}$ & neonate & infant & toddler & school-age child & adolescent & slim adult & normal-weight adult \\
\hline$<3 \mathrm{~kg}$ & $3-<5 \mathrm{~kg}$ & $5-<10 \mathrm{~kg}$ & $11-<19 \mathrm{~kg}$ & $19-<32 \mathrm{~kg}$ & $32-<56 \mathrm{~kg}$ & $56-<65 \mathrm{~kg}$ & $65-75 \mathrm{~kg}$ \\
\hline- & $0-<3$ months & $3-<12$ months & $1-<5$ years & $5-<10$ years & $10-<15$ years & - & - \\
\hline
\end{tabular}
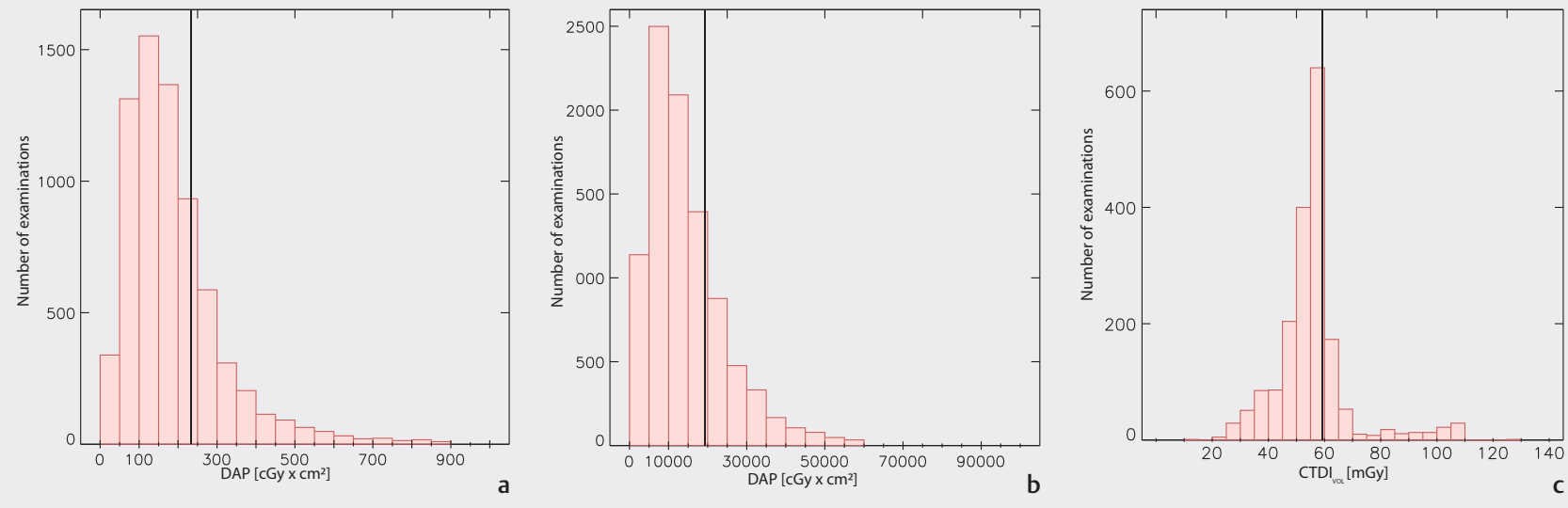

- Fig. 1 Acquired distribution a of the dose area product (DAP) for conventional X-ray examinations of the abdomen in AP/PA projection, b of the DAP for coiling of an intracranial aneurysm, and $\mathbf{c}$ of the volume CT dose index (CTDI vol ) for CT examinations of the head. The black vertical lines indicate the position of the 75th percentile used for setting the DRL value.

consensus with representatives of the Federal Ministry for the Environment, Nature Conservation and Nuclear Safety, the X-Ray Ordinance Working Group, the Commission on Radiological Protection, the medical authorities, the German Radiological Society, the German Society for Neuroradiology, the Society for Pediatric Radiology, the Professional Organization of German Radiologists, the German Society for Medical Physics, the German Electrical and Electronic Manufacturers' Association, and the above-named data-supplying institutions. As recommended by the ICRP and the European guidelines, the DRLs are defined based on the 75th percentiles of the particular dose distributions [7, 8, $35,36]$, with the plausibility of these values being carefully checked and the current DRLs from other countries being taken into consideration.

\section{Updated DRLS}

The dose distributions that served as the basis for the definition of

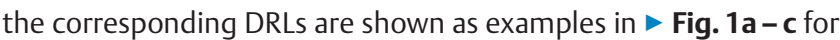
three different $\mathrm{X}$-ray procedures from the areas of conventional projection radiography, interventional radiology, and CT.

\section{X-ray procedures in adults}

- Conventional X-ray examinations ( $\downarrow$ Table 2): DRLs for X-ray examinations of the shoulder and hip were taken into consideration for the first time. In total, DRLs were defined for eight anatomical regions with up to two different projection directions. Compared to the DRLs defined in 2010, there was an average reduction of $16 \%$.

- Mammography ( $\triangleright$ Table 2): On average, the dose values provided by two reference centers of the mammography screening program were $21 \%$ lower than the values provided by the medical authorities. Compared to 2010, the DRL was reduced by $20 \%$.

- Fluoroscopy ( $>$ Table 3): DRLs were defined for six fluoroscopy examinations (one new). Compared to 2010, the DRLs were lowered by $19 \%$ on average.

- Interventional-radiologic procedures ( $>$ Table 4): DRLs were defined for ten interventions (nine new). The values for PTA were specified as a function of the body region in which the intervention is performed. The 25th, 50th, and 75th percentiles of the distributions of the fluoroscopy times are provided in $>$ Table 4 for further orientation for users. The old DRL for percutaneous coronary intervention ( $\mathrm{PCl}$; previously known as percutaneous transluminal coronary angioplasty, PTCA) was reduced by $20 \%$.

- CT examinations ( $\triangleright$ Table 5): DRLs (10 new) were defined for a total of $20 \mathrm{CT}$ examinations. Multiple DRLs were specified for one anatomical region for some examinations depending on the medical issue. - Table 5 provides additional scan limits and the standard scan lengths, $L_{\text {st }}$, of the relevant procedures for further orientation. The dose-related parameter values for examinations of the cranium, facial bones and the paranasal sinuses 
- Table $25^{\text {th }}, 50^{\text {th }}$ and $75^{\text {th }}$ percentiles of the distribution of dose-related parameters of projection radiographs and mammograms in adults as well as the updated DRLs and the corresponding rounded effective doses. In radiography, dose values are defined for a single projection, in mammography for each projection and breast.

\begin{tabular}{|c|c|c|c|c|c|}
\hline \multirow{2}{*}{$\begin{array}{l}\text { conventional projection } \\
\text { radiographs }\end{array}$} & \multicolumn{3}{|c|}{$\mathrm{DAP}\left[\mathrm{cGy} \cdot \mathrm{cm}^{2}\right.$ or $\left.\mu \mathrm{Gy} \cdot \mathrm{m}^{2}\right]$} & \multirow{2}{*}{$\begin{array}{l}\text { DRL }\left[\mathrm{cGy} \cdot \mathrm{cm}^{2}\right. \\
\left.\text { or } \mu G y \cdot \mathrm{m}^{2}\right]\end{array}$} & \multirow[t]{2}{*}{$D_{\text {eff }}[\mathrm{mSv}]$} \\
\hline & 25th percentiles & 50th percentiles & 75th percentiles & & \\
\hline skull AP/PA & 30 & 42 & 57 & 60 & 0.03 \\
\hline skull LAT & 27 & 37 & 50 & 50 & 0.02 \\
\hline shoulder & 10 & 16 & 27 & 25 & 0.02 \\
\hline thorax PA & 7 & 9 & 13 & 15 & 0.03 \\
\hline thorax LAT & 17 & 28 & 43 & 40 & 0.07 \\
\hline thoracic spine AP/PA & 48 & 77 & 110 & 110 & 0.2 \\
\hline thoracic spine LAT & 50 & 86 & 133 & 140 & 0.1 \\
\hline lumbar spine AP/PA & 89 & 140 & 203 & 200 & 0.4 \\
\hline lumbar spine LAT & 149 & 231 & 341 & 350 & 0.4 \\
\hline abdomen AP/PA & 102 & 157 & 228 & 230 & 0.5 \\
\hline pelvis AP/PA & 109 & 169 & 244 & 250 & 0.4 \\
\hline \multirow[t]{3}{*}{ hip } & 43 & 69 & 105 & 110 & 0.1 \\
\hline & \multicolumn{3}{|c|}{$\mathrm{AGD}[\mathrm{mSv}]$} & \multirow[t]{2}{*}{$\mathrm{DRL}[\mathrm{mSv}]$} & \multirow[t]{2}{*}{$\mathrm{D}_{\text {eff }}[\mathrm{mSv}]$} \\
\hline & 25th percentiles & 50th percentiles & 75th percentiles & & \\
\hline Mammography & 1.2 & 1.5 & 1.9 & 2.0 & -1 \\
\hline
\end{tabular}

DRL: diagnostic reference level, DAP: dose area product, $\mathrm{D}_{\text {eff: }}$ effective dose, AP: anterior-posterior, PA: posterior-anterior, LAT: lateral, AGD: average glandular dose.

1 The tissue weighting factors published in ICRP publication 103 [22] are the mean for both sexes. Thus, the concept of the effective dose cannot be used for a sex-specific analysis. The effective dose is not given.

- Table $325^{\text {th }}, 50^{\text {th }}$ and $75^{\text {th }}$ percentiles of the distribution of the dose-area product (DAP) of fluoroscopy examinations in adults as well as the updated DRLs and the corresponding rounded effective doses. Dose values correspond to the whole examination.

\begin{tabular}{|c|c|c|c|c|c|}
\hline \multirow[b]{2}{*}{ type of examination } & \multicolumn{3}{|c|}{$\operatorname{DAP}\left[\mathrm{cGy} \cdot \mathrm{cm}^{2}\right.$ or $\left.\mu G y \cdot \mathrm{m}^{2}\right]$} & \multirow{2}{*}{$\begin{array}{l}\text { DRL [cGy } \mathrm{cm}^{2} \text { or } \\
\left.\mu G y \cdot \mathrm{m}^{2}\right]\end{array}$} & \multirow[t]{2}{*}{$\mathrm{D}_{\text {eff }}[\mathrm{mSv}]$} \\
\hline & 25th percentiles & 50th percentiles & 75th percentiles & & \\
\hline CA & 1100 & 1800 & 2800 & 2800 & 5 \\
\hline ERCP & 550 & 1000 & 2600 & 2500 & 7 \\
\hline small intestine & 1000 & 1800 & 3200 & 3500 & 9 \\
\hline colon mono-contrast & 1100 & 1900 & 3000 & 3000 & 8 \\
\hline phlebography & 140 & 270 & 420 & 450 & 0.5 \\
\hline arteriography pelvis-leg & 1800 & 3100 & 4800 & 4800 & 7 \\
\hline
\end{tabular}

CA: coronary angiography, ERCP: endoscopic retrograde cholangiopancreatography.

relate to the head-CTDI test phantom (diameter of $16 \mathrm{~cm}$ ) and the other values relate to the body-CTDI test phantom (diameter of $32 \mathrm{~cm}$ ). Compared to the DRLs defined in 2010, the updated DLP values were reduced by $21 \%$ on average.

\section{X-ray procedures in children}

In conventional radiography, the DRL for AP exposures of the abdomen of neonates was added to the DRL catalog. In contrast, a DRL was not defined for CT scans of facial bones in children due to the low number of exposure values. In total, 17 DRLs were de- 
- Table $425^{\text {th }}, 50^{\text {th }}$ and $75^{\text {th }}$ percentiles of the distribution of the DAP and fluoroscopy times of interventional-radiologic procedures in adults as well as the updated DRLs and the corresponding rounded effective doses. Dose-related parameter values and effective doses correspond to the whole intervention.

\begin{tabular}{|c|c|c|c|c|c|c|c|c|}
\hline \multirow{2}{*}{$\begin{array}{l}\text { type of interven- } \\
\text { tional-radiologic } \\
\text { procedure }\end{array}$} & $\begin{array}{l}\text { DAP }\left[\mathrm{cGy} \cdot \mathrm{cm}^{2}\right. \\
\left.\text { or } \mu \mathrm{Gy} \cdot \mathrm{m}^{2}\right]\end{array}$ & $\begin{array}{l}\text { fluoroscopy } \\
\text { time [min] }\end{array}$ & $\begin{array}{l}\text { DAP }\left[\mathrm{cGy} \cdot \mathrm{cm}^{2}\right. \\
\left.\text { or } \mu G y \cdot \mathrm{m}^{2}\right]\end{array}$ & $\begin{array}{l}\text { fluoroscopy } \\
\text { time [min] }\end{array}$ & $\begin{array}{l}\text { DAP }\left[\mathrm{cGy} \cdot \mathrm{cm}^{2}\right. \\
\left.\text { or } \mu \mathrm{Gy} \cdot \mathrm{m}^{2}\right]\end{array}$ & $\begin{array}{l}\text { fluoroscopy } \\
\text { time [min] }\end{array}$ & \multirow[t]{2}{*}{$\begin{array}{l}\mathrm{DRL}^{1}\left[\mathrm{cGy} \cdot \mathrm{cm}^{2}\right. \\
\left.\text { or } \mu \mathrm{Gy} \cdot \mathrm{m}^{2}\right]\end{array}$} & \multirow[t]{2}{*}{$\begin{array}{l}D_{\text {eff }} \\
{[\mathrm{mSv}]}\end{array}$} \\
\hline & \multicolumn{2}{|c|}{ 25th percentiles } & \multicolumn{2}{|c|}{ 50th percentiles } & \multicolumn{2}{|c|}{ 75th percentiles } & & \\
\hline $\begin{array}{l}\text { thrombus aspira- } \\
\text { tion after stroke } \\
\text { (recanalization of } \\
\text { cerebral arteries) }\end{array}$ & 5100 & 12 & 9100 & 21 & 15800 & 35 & 18000 & 11 \\
\hline $\begin{array}{l}\text { coiling of a cerebral } \\
\text { aneurysm (EVAR of } \\
\text { the cerebral artery) }\end{array}$ & 7400 & 21 & 12100 & 34 & 19200 & 54 & 25000 & 16 \\
\hline $\mathrm{PCl}$ & 2000 & 5.2 & 3400 & 9.3 & 4900 & 13 & 4800 & 9 \\
\hline $\begin{array}{l}\text { combined CA } \\
\text { and } \mathrm{PCI}\end{array}$ & 2800 & 5.9 & 4000 & 9.5 & 5500 & 13 & 5500 & 10 \\
\hline TAVI & 2500 & 7.9 & 4900 & 12 & 8200 & 18 & 8000 & 15 \\
\hline \multicolumn{9}{|l|}{ EVAR } \\
\hline - thoracic aorta & 4700 & 7 & 11400 & 12 & 20300 & 19 & \multirow{3}{*}{23000} & 28 \\
\hline $\begin{array}{l}\text { - infrarenal ab- } \\
\text { dominal aorta }\end{array}$ & 5500 & 14 & 10800 & 21 & 20300 & 33 & & 32 \\
\hline $\begin{array}{l}\text { - suprarenal ab- } \\
\text { dominal aorta }\end{array}$ & 4700 & 14 & 9500 & 26 & 21800 & 52 & & 36 \\
\hline TACE & 6200 & 11 & 12100 & 17 & 22400 & 25 & 23000 & $39^{2}$ \\
\hline \multicolumn{9}{|l|}{ PTA of } \\
\hline - pelvis & 2200 & 7 & 4400 & 10 & 8700 & 17 & 9000 & 23 \\
\hline - thigh and knee & 800 & 7 & 1500 & 11 & 3500 & 18 & 4000 & 10 \\
\hline $\begin{array}{l}\text { - lower leg and } \\
\text { foot }\end{array}$ & 600 & 9 & 1000 & 17 & 2000 & 31 & 2500 & 6 \\
\hline \multicolumn{9}{|c|}{$\begin{array}{l}\text { PCI: percutaneous coronary intervention, TAVI: transcatheter aortic valve implantation, EVAR: endovascular aneurysm repair, TACE: transarterial } \\
\text { chemoembolization, PTA: percutaneous transluminal angioplasty. } \\
1 \text { The DRL refers to the dose-area product (DAP). } \\
2 \text { The effective dose for TACE refers to a procedure in the liver. }\end{array}$} \\
\hline
\end{tabular}

fined for conventional radiography ( $\vee$ Table 6), 4 DRLs for fluoroscopy ( $\vee$ Table 7), and 9 DRLs for CT ( the values from 2010, the DRLs for these three examination types were reduced on average by $27 \%, 48 \%$, and $16 \%$, respectively.

\section{Reference values}

According to $\S 8$, paragraph 2 Radiation Protection Act, operators of $\mathrm{X}$-ray devices are required to keep radiation exposure as low as possible even below the DRLs. Per definition, DRLs do not provide sufficient incentive for further optimization of the relevant $X$-ray procedures for the operators of approximately $75 \%$ of $X$-ray devices. As suggested by the ICRP, the 75th percentiles as well as the 25th and 50th percentiles of the corresponding dose distributions are listed in $\mathbf{r}$ Table $\mathbf{2}-\mathbf{8}$ and the corresponding percentiles of the distribution of fluoroscopy time are additionally provided in - Table 4 as reference values for further optimization of radiation exposure or for clarification of the reasons for DRLs being exceeded
[8]. When applying good medical practice and using modern equipment, it is possible for users to achieve the exposure level defined by the 50th percentiles. However, the patient dose must not be lowered to the point that the image quality is no longer sufficient to answer the medical question at hand in diagnostic radiology or to cause the intervention to fail in interventional radiology. Therefore, the image quality must be checked particularly at values below the 25 th percentiles. When using modern equipment, e. $g$. the simulation of scatter radiation grids in radiography or iterative image reconstruction in $\mathrm{CT}$, sufficient diagnostic image quality can be achieved even under the 25th percentiles in some cases [37]. Further reference values for examinations for which no DRLs have been defined are provided in the indicated study on CT practice in Germany [20]. 


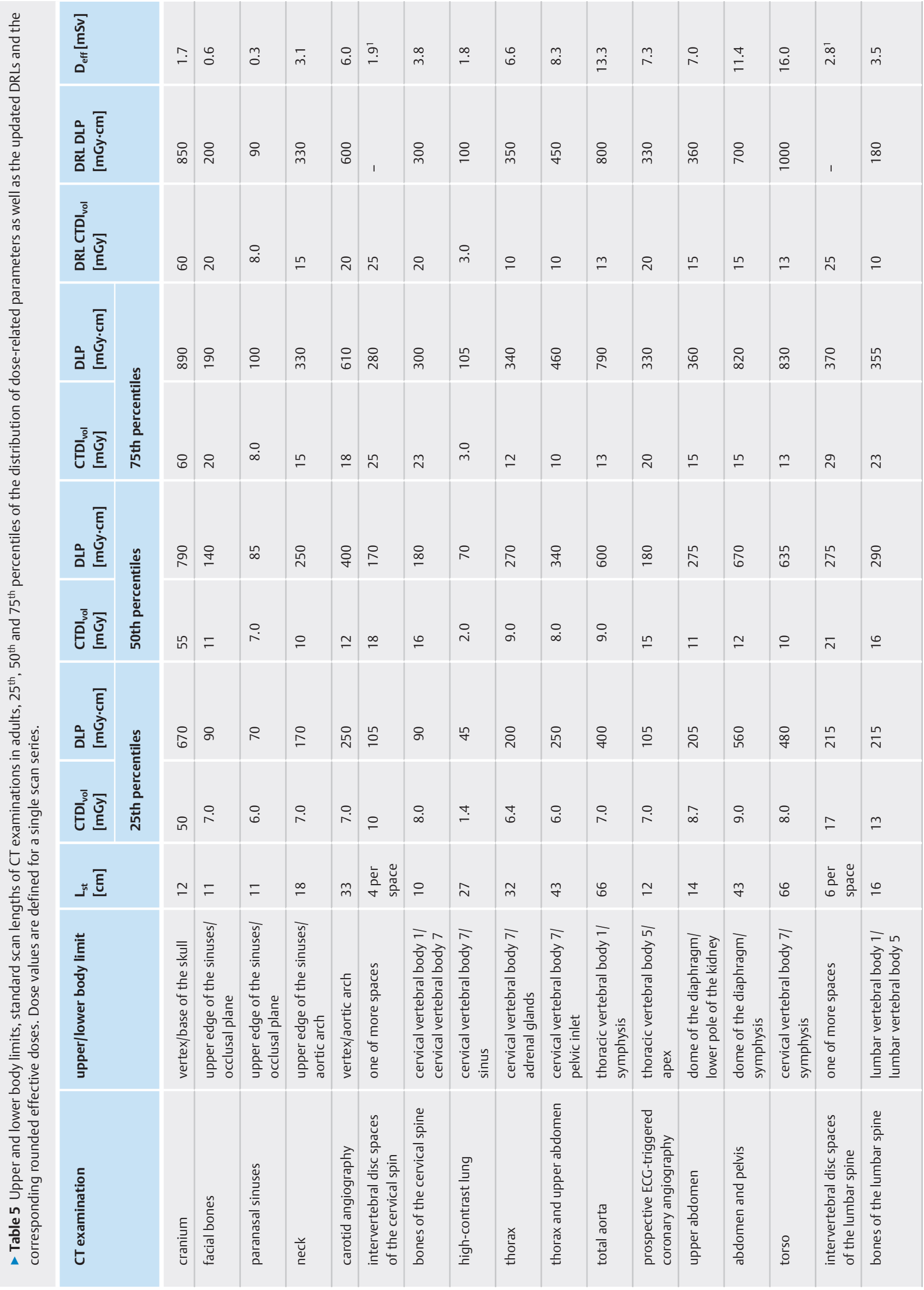




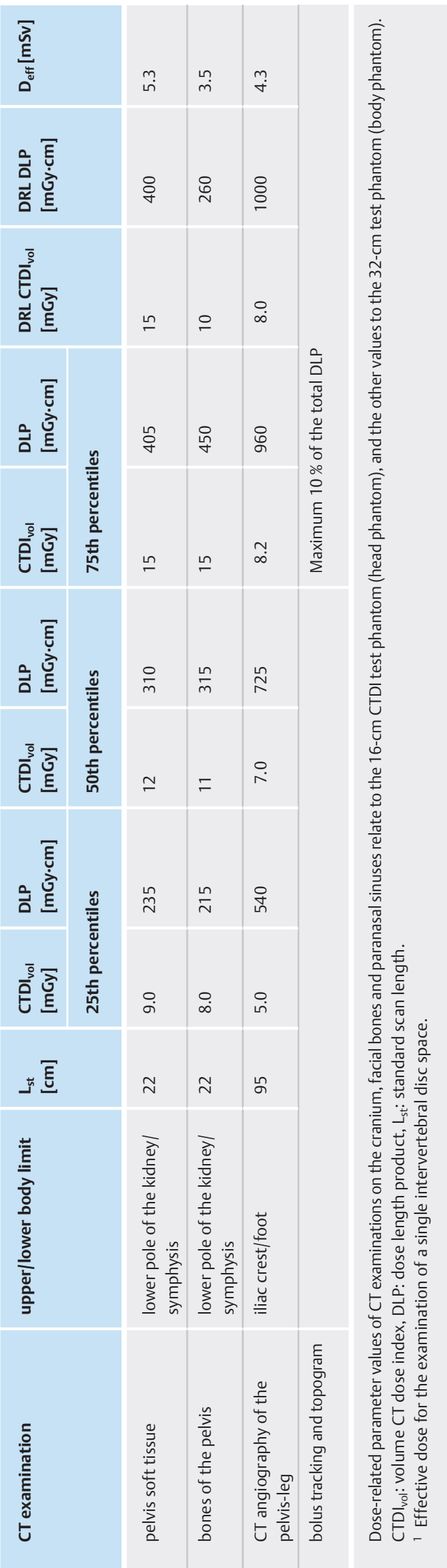

\section{Application of updated DRLs and reference values}

Since DRLs and reference values are used to optimize radiation applications, they relate to one projection direction and scan series in conventional radiography and $\mathrm{CT}$, respectively. The number of individual projections and projection directions or the number of scan series per examination is to be defined when determining the indication.

The protocol names of the various procedures involving radiation performed at a facility should be selected to that simple and clear assignment of the individual $X$-ray procedures to the applications defined in the DRL catalog can be performed even retrospectively, e. g. as part of a check by the medical authority. Internationally established nomenclature for radiation applications such as the RadLex Playbook [38] can be used for this purpose.

Specific information regarding various applications for which questions about the DRLs were submitted to the German Federal Office for Radiation Protection is provided in the following. Moreover, information as to how exposure parameters are to be modified for different medical issues, particularly in the case of CT procedures, is provided.

\section{Conventional X-rays}

- Abdomen: The low percentiles of the relevant dose distribution compared to those for $\mathrm{X}$-rays of the pelvis can be explained by the fact that dose data for the abdomen includes a high percentage of images used to survey the abdomen in emergency situations with a lower image quality.

\section{Fluoroscopy}

- Cone beam computed tomography (CBCT $)^{1}$ : The sum of dose fractions of conventional 2D fluoroscopy and possible CBCT examinations is to be compared with the DRL.

- ERCP: Compliance with the specified DRL can be ensured even in interventional-radiologic procedures.

\section{Interventional-radiologic procedures}

- The DRLs for interventional-radiologic procedures outside the heart were updated again in 2018. Under consideration of the complexity and subsequent variability of these interventions, the relevant DRLs were carefully adjusted in comparison to the values from 2016.

- CBCT: The sum of dose fractions of conventional 2D procedures and possible CBCT examinations is to be compared with the relevant DRL.

- If multiple interventional-radiologic procedures and/or fluoroscopy scans are combined in the same body region, the corresponding DRLs are to be added together. An exception here is combined coronary angiography (CA) and $\mathrm{PCl}$ (see below).

- Combined coronary angiography (CA) and PCl: Combined CA and $\mathrm{PCl}\left(5500 \mathrm{cGy} \cdot \mathrm{cm}^{2}\right)$ is usually not PCI $\left(4800 \mathrm{cGy} \cdot \mathrm{cm}^{2}\right)$ fol-

1 The method is also referred to as digital volume tomography (DVT) or flat detector CT (FDCT). 
- Table $625^{\text {th }}, 50^{\text {th }}$ and $75^{\text {th }}$ percentiles of the distribution of the DAP of pediatric projection radiographs as well as the updated DRLs. Dose values are defined for a single projection.

\begin{tabular}{|c|c|c|c|c|}
\hline \multirow[t]{2}{*}{ weight class or age } & \multicolumn{3}{|c|}{$\mathrm{DAP}\left[\mathrm{cGy} \cdot \mathrm{cm}^{2}\right.$ or $\left.\mu \mathrm{Gy} \cdot \mathrm{m}^{2}\right]$} & \multirow{2}{*}{$\begin{array}{l}\text { DRL }\left[\mathrm{cGy} \cdot \mathrm{cm}^{2} \text { or }\right. \\
\left.\mu G y \cdot \mathrm{m}^{2}\right]\end{array}$} \\
\hline & 25th percentiles & 50th percentiles & 75th percentiles & \\
\hline skull AP infant ( $3-<12$ months) & 6.0 & 9.0 & 13 & 12 \\
\hline skull AP toddler ( $1-<5$ years) & 12 & 17 & 24 & 24 \\
\hline skull LAT infant ( $3-<12$ months) & 5.5 & 8.0 & 11 & 10 \\
\hline skull LAT toddler ( $1-<5$ years) & 10 & 14 & 21 & 20 \\
\hline thorax AP/PA premature infant $(<3 \mathrm{~kg})$ & 0.1 & 0.1 & 0.2 & 0.3 \\
\hline thorax AP/PA neonate ( $3-<5 \mathrm{~kg} ; 0-<3$ months) & 0.2 & 0.3 & 0.5 & 0.5 \\
\hline thorax AP/PA infant ( $5-<10 \mathrm{~kg} ; 3-<12$ months) & 0.5 & 0.7 & 1.1 & 1.0 \\
\hline thorax AP/PA toddler (10 - <19 kg; $1-<5$ years) & 0.9 & 1.3 & 2.0 & 2.0 \\
\hline $\begin{array}{l}\text { thorax AP/PA school-age child }(19-<32 \mathrm{~kg} \text {; } \\
5-<10 \text { years) }\end{array}$ & 1.6 & 2.5 & 3.5 & 3.5 \\
\hline thorax LAT toddler ( $10-<19 \mathrm{~kg} ; 1-<5$ years) & 1.0 & 1.5 & 2.7 & 2.5 \\
\hline thorax LAT school-age child ( $19-<32 \mathrm{~kg} ; 5-<10$ years) & 3.0 & 4.5 & 5.8 & 5.0 \\
\hline abdomen AP/PA neonate ( $3-<5 \mathrm{~kg} ; 0-<3$ months) & 0.1 & 0.4 & 0.8 & 2.0 \\
\hline abdomen AP/PA infant ( $5-<10 \mathrm{~kg} ; 3-<12$ months) & 2.5 & 3.5 & 5.0 & 5.0 \\
\hline abdomen AP/PA toddler (10 - <19 kg; $1-<5$ years) & 3.5 & 6.5 & 11 & 10 \\
\hline $\begin{array}{l}\text { abdomen AP/PA school-age child }(19-<32 \mathrm{~kg} \text {; } \\
5-<10 \text { years })\end{array}$ & 6.5 & 12 & 15 & 20 \\
\hline pelvis AP/PA toddler ( $10-<19 \mathrm{~kg} ; 1-<5$ years) & 3.5 & 6.5 & 12 & 12 \\
\hline pelvis AP/PA school-age child ( $19-<32 \mathrm{~kg} ; 5-<10$ years) & 11 & 19 & 28 & 25 \\
\hline
\end{tabular}

Table $725^{\text {th }}, 50^{\text {th }}$ and $75^{\text {th }}$ percentiles of the distribution of the DAP of miction cystourethrography $(\mathrm{MCU})$ in children of varying weights and ages as well as the updated DRLs. Dose values are defined for the total examination.

\begin{tabular}{|c|c|c|c|c|}
\hline \multirow[t]{2}{*}{ weight class or age } & \multicolumn{3}{|c|}{ DAP $\left[\mathrm{cGy} \cdot \mathrm{cm}^{2}\right.$ or $\left.\mu G y \cdot \mathrm{m}^{2}\right]$} & \multirow{2}{*}{$\begin{array}{l}\text { DRL [cGy } \cdot \mathrm{cm}^{2} \\
\left.\text { or } \mu \mathrm{Gy} \cdot \mathrm{m}^{2}\right]\end{array}$} \\
\hline & 25th percentiles & 50th percentiles & 75th percentiles & \\
\hline MCU in neonate ( $3-<5 \mathrm{~kg} ; 0-<3$ months) & 1.4 & 2.1 & 3.8 & 5.0 \\
\hline MCU in infant ( $5-<10 \mathrm{~kg} ; 3-<12$ months) & 3.1 & 5.0 & 8.9 & 10 \\
\hline MCU in toddler (10 - < $19 \mathrm{~kg} ; 1-<5$ years) & 5.3 & 10 & 19 & 18 \\
\hline MCU in school-age child ( $19-<32 \mathrm{~kg} ; 5-<10$ years) & 11 & 21 & 35 & 30 \\
\hline
\end{tabular}

lowing completed CA (2800 cGy·cm²), but rather therapeutic intervention sequences under fluoroscopy guidance following shorter diagnostic fluoroscopy and imaging sequences. On the whole, the number of fluoroscopy and imaging sequences and thus the dose are lower than the sum of CA and PCI.

- Endovascular aneurysm repair (EVAR) of the aorta: Even if for the sake of simplicity only one DRL for EVAR was defined independent of the anatomical region in 2018 , it is recommended due to the potential variations in the complexity of interventions to record the section of the aorta (thoracic aorta, suprarenal abdominal aorta, or infrarenal abdominal aorta) in which the particular intervention was performed [19].
- Percutaneous transluminal angioplasty (PTA): A differentiation is made between the pelvis, thigh-knee, and lower leg-foot. If the blood vessel to be treated is located on the border of adjacent regions, the greater DRL is to be applied.

\section{CT examinations}

- CBCT: In principle, the DRLs defined for conventional CT are also valid for examinations using CBCT devices if the DLP is displayed or a conversion of the dose-related parameters (DAP to $D(P)$ is possible. 


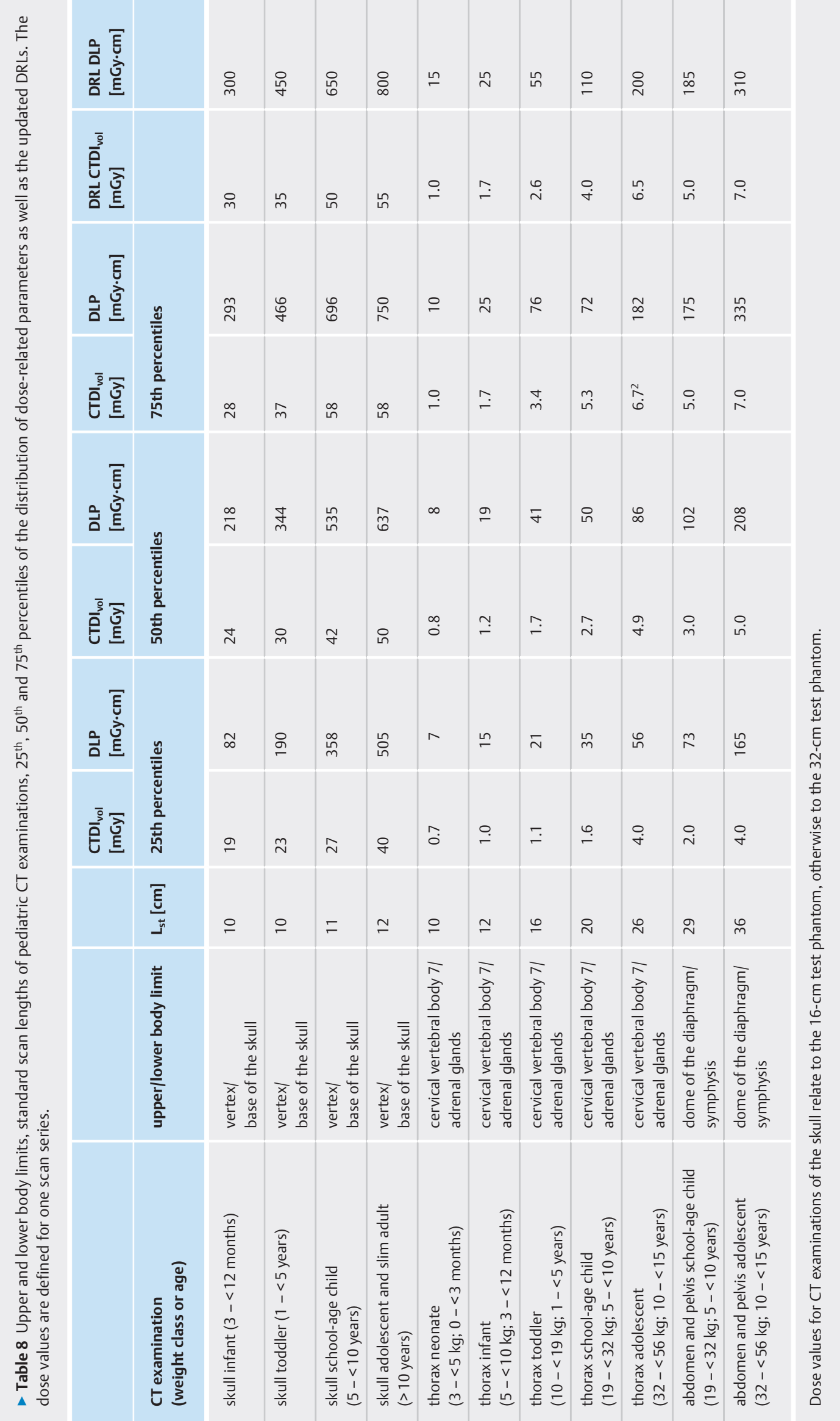


- Scan lengths: The scan lengths specified in $\mathbf{r}$ Table 5 relate to the average of the values calculated for the reference woman and reference man.

- Test phantom: Complete recording of radiation exposure includes the CTDI ${ }_{\text {vol }}$ and DLP as well as information about the "CT dosimetry phantom", i. e., specification of which CTDI test phantom was used to measure the $C T D I_{\text {vol }}$. Without this specification, the dose information is incomplete. Standard IEC $60601-2-44$, which has been valid since 2012, states that the $16-\mathrm{cm}$ test phantom is used for head CT protocols and the $32-\mathrm{cm}$ test phantom is used for body CT protocols (including pediatric examinations of the torso) by the manufacturer in devices installed after 2012, unless modified by the user. In principle, it is recommended to ask the manufacturer which test phantom is used for which CT protocols (particularly for examinations of the neck, spine, extremities, and in pediatric examinations). Information about the test phantom should also be provided in the (DICOM) dose report. By multiplying by the factor 1.7, the CTDI ${ }_{\text {vol- }}$ and DLP values for the $32-\mathrm{cm}$ test phantom can be converted approximately to the corresponding values for the $16-\mathrm{cm}$ test phantom.

- Base of the skull: It is recommended to use the same CTDI ${ }_{\text {vol }}$ for examinations of the base of the skull as in examinations of the cranium. The scan length is approximately $4-5 \mathrm{~cm}$ with an optimal gantry tilt or positioning of the head. The DLP of the cranium must be reduced accordingly.

- Facial bones: In the case of partial examinations of the facial bones, such as examination of the jaw, the scan length is to be reduced to approximately $4 \mathrm{~cm}$ (and the DLP is to be adjusted accordingly).

- Intervertebral disc space of the cervical spine/lumbar spine: A DLP was not defined since the number of intervertebral disc spaces to be examined depends on the individual clinical issue.

- Thorax: To rule out a pulmonary embolism, the scan ranges from the upper edge of the aortic arch to the dome of the diaphragm $[39,40]$ with a standard scan length of approx. $16 \mathrm{~cm}$. The $\mathrm{CTDI}_{\mathrm{vol}}$ can be reduced significantly to less than $10 \mathrm{mGy}$ [41]. The DLP must be lowered proportionally.

- Aorta: In the case of examinations of parts of the aorta, the scan length and thus the DLP must be reduced accordingly (e. g. $\mathrm{DLP}=420 \mathrm{mGy} \cdot \mathrm{cm}$ for thoracic aorta, $\mathrm{DLP}=460 \mathrm{mGy} \cdot \mathrm{cm}$ for abdominal aorta[20]).

- Prospective ECG-triggered coronary angiography: Coronary CT angiography with retrospective ECG comparison is not recommended since this method is associated with a significant increase in patient dose by at least $100 \%$ in comparison to the prospective ECG-triggered method [20].

- High-contrast examinations: As a rule, dose-relevant examination parameter values in high-contrast examinations are to be significantly reduced compared to the corresponding values in medical issues involving soft tissue in the same body region since greater image noise can be tolerated in reporting in the case of high-contrast imaging due to the large window width (typically reconstruction of thin slices with a high-contrast kernel).

- High-contrast examination of the lung is a low-dose examination with a focus solely on the visualization of the lung parenchyma with differentiation from air with greatly limited evaluation of soft tissue. The scan region stretches from the tip of the lung to the edge of the sinus (also see [42]).

- If adjacent body regions (e. g. pelvic bone when examining the bones of the lumbar spine) are included in high-contrast examinations of bone structures, the DLP can be increased in relation to the scan length while maintaining the $\mathrm{CTDI}_{\mathrm{vol}}$. In the case of targeted medical issues (e. g. when ruling out hairline fractures in the skeleton), the CTDI ${ }_{\text {vol }}$ and thus also the DLP can be slightly greater than the DRL.

- In the case of high-contrast examinations to search for stones in the case of acute colic in the region of the kidneys or the urinary tract, the CTDI ${ }_{\text {vol }}$ can be lowered to $5 \mathrm{mGy}$

[41]. The scan length and thus the DLP are to be adapted to the particular medical issue.

- Bolus tracking and topograms: The DLP of bolus tracking and topograms should not comprise more than $10 \%$ of the total DLP of the corresponding CT examination.

\section{Outlook}

According to the ICRP and EU, the DRL concept represents an instrument to be primarily used by equipment operators to effectively identify the diagnostic and interventional X-ray procedures that may require optimization. However, the ICRP also states that the DRL concept is currently insufficiently known and implemented in many facilities - if at all. In light of international requirements (e.g. the EURATOM basic standards [36]) and their inclusion in German law, an expert discussion regarding further development and the resolution of existing problems in the implementation of the DRL concept in Germany was held. The results of the expert discussion can be summarized in the following recommendations for equipment operators:

- Local reference values: Despite the significant expansion of the DRL catalog, there are still numerous radiation applications (e. g. dental radiographs and imaging of the extremities) for which no DRLs have been defined. If such applications of radiation are used frequently at a facility, it is recommended to define local reference values on the basis of the 50th percentiles of a larger patient population. However, local reference values can also be defined for applications of radiation for which national DRLs have already been defined. Since the DRLs are defined based on the 75th percentiles of the national dose distributions, even the updated DRLs can be significantly undercut when using new equipment and applying good medical practice. The definition of local reference values provides an incentive for further optimization to levels below the valid national DRLs in a facilityspecific manner $[43,44]$.

- Dose management systems: To date, exceeding of DRLs and radiation applications that are not optimized with respect to radiation hygiene have tended to be discovered at many facilities by accident, e. g. during checks by the medical authority. Since modern medical systems in interventional radiology and computed tomography must be able to transfer dose-related parameters to the examination records, dose-related parameters should be continuously recorded and systematically and clearly evaluated with the help of a dose management system 
$[45,46]$. As various studies have shown, this is essential for systematic protocol optimization and for a continuous comparison with national DRLs and local reference values [47 - 49].

- Systematic dose adjustment to patient stature: For physical reasons, optimization of radiation applications in radiology depends on the stature of the patient. Therefore, it is expressly recommended to record parameters that characterize patient stature (e. g. BMI, body weight, body diameter, and the sizespecific dose estimate (SSDE) [50]) and to systematically include them in the optimization of the radiation application. Various studies have shown that radiation applications can be consequently systematically optimized and any cases in which the DRLs are exceeded can be explained (e. g. [51, 52]).

- Radiation protection team: Systematic and consistent optimization of radiation applications, particularly the use of DRLs and local reference values, requires the development and implementation of a radiation protection concept together with physicians, medical physics experts, radiology technicians, and radiological safety officers of a medical facility. This team should make concrete statements regarding the examination protocols to be used (including collimation/scan length, voltage) as a function of patient stature, the use of modern dose-reducing techniques, the use of radiation protection means/shielding and the approach in interventional-radiologic procedures. On the whole, the radiation protection team should promote the proper use of X-ray equipment in the entire radiology department or practice and optimization of processes and protocols.

\section{Conflict of Interest}

The authors declare that they have no conflict of interest.

\section{Acknowledgement}

We thank all the institutions that reported dose values to the German Federal Office for Radiation Protection for updating the DRLs as well as the participants of the expert discussions and email consultations for their constructive contributions.

\section{References}

[1] Nekolla EA, Schegerer AA, Griebel J et al. Häufigkeit und Dosis diagnostischer und interventioneller Röntgenanwendungen. Der Radiologe 2017; 57: 555-562

[2] Amis ES, Butler PF. ACR white paper on radiation dose in medicine: three years later. J Am Coll Radiol 2010; 7: 865-870

[3] Berrington de González A, Darby S. Risk of cancer from diagnostic X-rays: estimates for the UK and 14 other countries. The Lancet 2004; 363: $345-351$

[4] Bundesrepublik Deutschland. Verordnung über den Schutz vor Schäden durch Röntgenstrahlung (Röntgenverordngung - RöV). BGBI 2014; I: 2010

[5] International commission on radiological protection (ICRP). Radiological protection and safety in medicine. ICRP Publication 73. Ann ICRP 1996; 26: $1-47$

[6] International commission on radiological protection (ICRP). Radiological protection in medicine. ICRP Publication 105. Ann ICRP 2007; 37: 1-63
[7] European commission. Guidance on diagnostic reference levels (DRLs) for medical expsoures. Radiation Protection 1999. 109

[8] International commission on radiological protection (ICRP). Diagnostic reference levels in medical imaging. ICRP Publication 135. Ann ICRP 2017; 46: 1-143

[9] Veit R, Guggenberger R, Noßke D et al. Diagnostische Referenzwerte für Röntgenuntersuchungen. Der Radiologe 2010; 50: 907-912

[10] Bundesministerium für Umwelt, Naturschutz und Reaktorsicherheit. Qualitätssicherung durch ärztliche und zahnärztliche Stellen. GMBI 2015; 51: 1026

[11] Bundesamt für Strahlenschutz (BfS). Bekanntmachung der diagnostischen Referenzwerte für radiologische und nuklearmedizinische Untersuchungen. Bundesanzeiger. 143 05.08.2003; 17503

[12] Bundesamt für Strahlenschutz (BfS). Bekanntmachung der aktualisierten diagnostischen Referenzwerte für diagnostische und interventionelle Röntgenuntersuchungen. Bundesanzeiger.111 28.07.2010; 2594

[13] Bundesamt für Strahlenschutz (BfS). Bekanntmachung der aktualisierten diagnostischen Referenzwerte für interventionelle Röntgenuntersuchungen. Bundesanzeiger. AT 03.09.2018 B8

[14] Bundesamt für Strahlenschutz (BfS). Bekanntmachung der aktualisierten diagnostischen Referenzwerte für diagnostische und interventionelle Röntgenuntersuchungen. Bundesanzeiger. AT 15.07.2016 B8

[15] Institut für angewandte Qualitätsförderung und Forschung im Gesundheitswesen AQUA GmbH. Qualitätsreport 2012. 2013. 1/08.2013

[16] Institut für angewandte Qualitätsförderung und Forschung im Gesundheitswesen AQUA GmbH. Qualitätsreport 2013. 2014. 1/08.2014

[17] Institut für angewandte Qualitätsförderung und Forschung im Gesundheitswesen AQUA GmbH. Qualitätsreport 2014. 2015. 1/08.2015

[18] Heuser L], Arnold CN, Morhard D et al. DeGIR-Qualitätsreport 2011 Bericht über die Behandlungsqualität minimalinvasiver Methoden. Teil 1: Verfahren zur Rekanalisation eingeengter und verschlossener Arterien. Fortschr Röntgenstr 2012; 184: 570-576

[19] Heuser LJ, Arnold CN, Morhard D et al. Qualitätsreport 2011: Bericht üfer die Behandlungsqualität minimalinvasiver Methoden - Teil 2: Interventionelle Therapie (EVAR) von Aortenaneurysmen. Fortschr Röntgenstr 2013; 185: 709-719

[20] Schegerer AA, Nagel HD, Stamm G et al. Current CT practice in Germany: Results and implications of a nationwide survey. Eur J Radiol 2017; 90: $114-128$

[21] International commission on radiological protection (ICRP). Adult reference computational phantoms. ICRP Publication 110. Ann ICRP 2009; 39: $1-165$

[22] International commission on radiological protection (ICRP). Recommendations of the international commission on radiological protection. ICRP Publication 103. Ann ICRP 2007; 37: 1-123

[23] Stamm G, Nagel HD. CT-Expo - a novel program for dose evaluation in CT. Fortschr Röntgenstr 2002; 174: 1570-1576

[24] STUK - Radiation and nuclear safety authority Helsinki. PCXMC dose calculations. 2.0.1 ed2008

[25] Bundesärztekammer. Leitlinie der Bundesärztekammer zur Qualitätssicherung in der Computertomographie. 2007

[26] Bundesärztekammer. Leitlinie der Bundesärztekammer zur Qualitätssicherung in der Röntgendiagnostik - Qualitätskriterien röntgendiagnostischer Untersuchungen 2007.

[27] Khelassi-Toutaoui N, Berkani Y, Tsapaki V et al. Experimental evaluation of PCXMC and prepare codes used in conventional radiology. Radiation Protection Dosimetry 2008; 131: 374-378

[28] Brix G, Lechel U, Veit R et al. Assessment of a theoretical formalism for dose estimation in CT: an anthropomorphic phantom study. Eur Radiol 2004; $14: 1275-1284$ 
[29] National council on radiation protection and measurement (NCRP). Ionizing Radiation Exposure of the Population of the United States. 2009. Report 160

[30] European commission. Guidance for protection of unborn children and infants irradiated due to parental medical exposures. Radiation Protection 1998. 100

[31] European commission. European guidelines on diagnostic reference levels for paediatric imaging. Radiation protection 2018. 185

[32] International commission on radiological protection (ICRP). Basic anatomical and physiological data for use in radiological protection reference values. ICRP Publication 89. Ann ICRP 2002; 32: 1 - 165

[33] Galanski M, Nagel HD, Stamm G. Pediatric CT exposure practice in the federal republic of Germany. BMUB Forschungsvorhaben 2006; StSch 4470

[34] Kiljunen T, Järvinen $H$, Savolainen S. Diagnostic reference levels for thorax X-ray examinations of paediatric patients. Br J Radiol 2007; 80: $452-459$

[35] Council of the European Union. 97/43/Euratom on health protection of individuals against the dangers of ionizing radiation in relation to medical exposure and repealing Directive 84/466/Euratom. Official Journal of the EU 1997; L180: $22-27$

[36] Council of the European Union. 2013/59/Euratom on basic safety standards for protection against the dangers arising from exposure to ionising radiation and repealing Directives 89/618/Euratom, 90/641/ Euratom, 96/29/Euratom, 97/43/Euratom and 2003/122/Euratom. Official Journal of the EU 2014; L13: 1 - 73

[37] Renger B, Brieskorn C, Toth V et al. Evaluation of dose reduction potentials of a novel scatter correction software for bedside chest x-Ray imaging. Radiat Prot Dosimetry 2016; 169: 60-67

[38] Wang KC, Patel JB, Vyas B et al. Use of radiology procedure codes in health care: the need for standardization and structure. RadioGraphics 2017; 37: 1099-1110

[39] Mayo ], Thakur Y. Pulmonary CT angiography as first-line imaging for PE: image quality and radiation cose considerations. Am J Roentgenol 2012; 200: $522-528$

[40] Atalay MK, Walle NL, Grand DJ et al. Scan length optimization for pulmonary embolism at CT angiography: analysis based on the three-dimensional spatial distribution of 370 emboli in 100 patients. Clinical Radiology 2011; 66: 405 -411
[41] Schweizerisches Bundesamt für Gesundheit (BAG). Diagnostische Referenzwerte in der Computertomographie, Wegleitung. R-06-06wd (2018).

[42] Nagel HD, Hering KG, Hieckel HG et al. Mitteilung der DRG: Protokollempfehlung der AG DRauE zur Durchführung von Low-Dose-VolumentHRCT-Untersuchungen der Lunge. Fortschr Röntgenstr 2017; 189: $553-575$

[43] Heilmaier C, Zuber N, Berthold C et al. Establishing local diagnostic reference levels in IR procedures with dose management software. Journal of Vascular and Interventional Radiology 2017; 28: 429-441

[44] McFadden S, Hughes C, D'Helft C et al. The establishment of local diagnostic reference levels for paediatric interventional cardiology. Radiography 2013; 19: 295 - 301

[45] Boos J, Meineke A, Bethge OT et al. Dose monitoring in radiology departments: Status quo and future perspectives. Fortschr Röntgenstr 2016; 188: $443-450$

[46] Gress DA, Dickinson RL, Erwin WD et al. AAPM medical physics practice guideline 6.a.: Performance characteristics of radiation dose index monitoring systems. Journal of Applied Clinical Medical Physics 2017; 18: $12-22$

[47] Heilmaier C, Niklaus Z, Berthold C et al. Improving patient Safety: implementing dose monitoring software in fluoroscopically guided interventions. Journal of Vascular and Interventional Radiology 2015; 26: $1699-1709$

[48] Heilmaier C, Zuber N, Weishaupt D. Implementation of a patient dose monitoring system in conventional digital X-ray imaging: initial experiences. Eur Radiol 2017; 27: 1021 - 1031

[49] Schäfer S, Alejandre-Lafont E, Schmidt T et al. Dose management for $\mathrm{x}$-ray and CT: systematic comparison of exposition values from two institutes to diagnostic reference levels and use of results for optimisation of exposition. Fortschr Röntgenstr 2014; 186: 785-794

[50] American Association of Physicists in Medicine (Task Group 204). AAPM report: size-specific dose estimates (SSDE) in pediatric and adult body CT examinations. College Park, MD 20740-3846: American Association of Physicists in Medicine 2011

[51] Christner JA, Braun NN, Jacobsen M et al. Size-specific dose estimates for adult patients at CT of the torso. Radiology 2012; 265: $841-847$

[52] Menke J. Comparison of different body size parameters for individual dose adaptation in body CT of adults. Radiology 2005; 236: $565-571$ 